\title{
Conserved Single Residue in the BK Potassium Channel Required for Activation by Alcohol and Intoxication in C. elegans
}

\author{
Scott J. Davis, Luisa L. Scott, Kevin Hu, and Jonathan T. Pierce-Shimomura \\ Waggoner Center for Alcohol and Addiction Research, Institute of Neuroscience, Center for Learning and Memory, Center for Brain, Behavior, and \\ Evolution, and Department of Neuroscience, The University of Texas at Austin, Texas 78712
}

\begin{abstract}
Alcohol directly modulates the BK potassium channel to alter behaviors in species ranging from invertebrates to humans. In the nematode Caenorhabditis elegans, mutations that eliminate the BK channel, SLO-1, convey dramatic resistance to intoxication by ethanol. We hypothesized that certain conserved amino acids are critical for ethanol modulation, but not for basal channel function. To identify such residues, we screened $C$. elegans strains with different missense mutations in the SLO-1 channel. A strain with the SLO-1 missense mutation T381I in the RCK1 domain was highly resistant to intoxication. This mutation did not interfere with other BK channeldependent behaviors, suggesting that the mutant channel retained normal in vivo function. Knock-in of wild-type versions of the worm or human BK channel rescued intoxication and other BK channel-dependent behaviors in a slo-1-null mutant background. In contrast, knock-in of the worm T381I or equivalent human T352I mutant BK channel selectively rescued BK channel-dependent behaviors while conveying resistance to intoxication. Single-channel patch-clamp recordings confirmed that the human BK channel engineered with the T352I missense mutation was insensitive to activation by ethanol, but otherwise had normal conductance, potassium selectivity, and only subtle differences in voltage dependence. Together, our behavioral and electrophysiological results demonstrate that the T352I mutation selectively disrupts ethanol modulation of the BK channel. The T352I mutation may alter a binding site for ethanol and/or interfere with ethanol-induced conformational changes that are critical for behavioral responses to ethanol.
\end{abstract}

Key words: behavior; BK channel; C. elegans; ethanol

\section{Introduction}

The large-conductance voltage- and calcium-activated potassium (BK) channel mediates a wide variety of physiological processes, including neurotransmitter release, action potential bursts, and afterhyperpolarization (Lancaster and Nicoll, 1987; Robitaille et al., 1993; Golding et al., 1999). The BK channel also mediates ethanol intoxication and/or tolerance in worms, flies, mice, and humans (Davies et al., 2003; Cowmeadow et al., 2005, 2006; Martin et al., 2008; Kreifeldt et al., 2013). Many studies have demonstrated BK channel activity is altered by pharmacologically relevant concentrations (20-100 mM) of ethanol (Chu and Treistman, 1997; Jakab et

Received March 2, 2014; revised June 3, 2014; accepted June 11, 2014.

Author contributions:S.J.D., L.L.S., and J.T.P.-S. designed research;S.J.D. and K.H. performed research;S.J.D. and J.T.P.-S. contributed unpublished reagents/analytic tools;S.J.D., L.L.S., and J.T.P.-S. analyzed data;S.J.D., L.L.S., and J.T.P.-S. wrote the paper.

Funds were provided by National Research Service Award (NRSA) award F31AA021641 to S.D.; by the National Institute on Alcohol Abuse and Alcoholism (NIAAA); and the Waggoner Center, ABMRF, NIAAA-National Institutes of Health (NIH) grants R03AA020195 and R01AA020992; and the University of Texas, Austin, start-up funds to J.T.P. We thank M. Edgley for pointing out the power of the Million Mutation Project; J. Rand and the Caenorhabditis Genetic Center (funded by the NIH) for reagents; J. Mayfield for critical editing; and N. Atkinson, R. Aldrich, and A. Harris for helpful comments.

The authors declare no competing financial interests.

Correspondence should be addressed to Jonathan T. Pierce-Shimomura, University of Texas at Austin, Neuroscience Department, 2506 Speedway NMS5.234, Mailcode C7350, Austin, TX78712. E-mail: jonps@austin.utexas.edu. DOI:10.1523/JNEUROSCI.0838-14.2014

Copyright $\odot 2014$ the authors $\quad 0270-6474 / 14 / 349562-12 \$ 15.00 / 0$ al., 1997; Dopico et al., 1998, 2003; Walters et al., 2000; Brodie et al., 2007). Modulation of the BK channel by ethanol is also evident in reconstituted lipid bilayers demonstrating that ethanol directly acts on the protein (Chu et al., 1998).

A few studies have mechanistically explored how ethanol modulates the BK channel in vitro. For example, phosphorylation of two residues near the first two transmembrane domains switches the action of ethanol from activation to inhibition in the bovine BK channel (Liu et al., 2006). Ethanol modulation further depends on the presence of intracellular calcium and specific residues required for calcium activation, as well as the intracellular tail (Liu et al., 2008, 2013).

We previously showed that mutants with predicted null mutations in the worm BK channel SLO-1 are extremely resistant to ethanol intoxication as measured by egg laying and locomotion (Davies et al., 2003). In Caenorhabditis elegans, egg laying is a behavior governed by a defined neural circuit (Waggoner et al., 1998). Ethanol reduces the rate of egg laying by $90 \%$ in wild-type worms compared with only $0-30 \%$ in slo-1 (null) mutant worms (Davies et al., 2003). Ethanol reduces the rate of locomotion by $70 \%$ in wild-type worms and only $35 \%$ in slo-1(null). In addition, the native SLO-1 channel excised in patches of neuronal membrane from C. elegans was activated by ethanol (20-100 mm; (Davies et al., 2003).

Our previous work demonstrated that the $\mathrm{BK}$ channel is critical for intoxication in C. elegans, but did not divulge a molecular 
mechanism for ethanol action. In this study, we exploited the facile genetics of $C$. elegans and screened mutant worms with novel missense mutations in the BK channel. Our aim was to identify an amino acid residue that mediates ethanol effects but is not critical for normal basal activity in vivo. We identified a mutation in a conserved residue that was essential for both ethanol modulation of the $\mathrm{BK}$ channel in vitro and intoxication in vivo without altering single-channel properties or other BK channeldependent behaviors.

\section{Materials and Methods}

Animals. C. elegans strains were grown at $20^{\circ} \mathrm{C}$ and fed OP50 strain bacteria seeded on Nematode Growth Media (NGM) agar plates as described previously (Brenner, 1974). Worms cultured on plates contaminated with fungi or other bacteria were excluded from this study. The N2 Bristol strain of $C$. elegans was used as the wild-type reference. The slo1 (null) strain used in this study was NM1968 harboring allele js379 (Wang et al., 2001). Additional strains from the Million Mutation Project (Thompson et al., 2013) with predicted missense mutations in the slo-1 gene were also used, including: VC40372, VC40853, VC40064, VC40938, VC30161, VC40899, VC40774, VC40641, VC40384, VC40804, VC40392, VC40468, VC40143, VC40062, VC20545, VC40416, VC20244, VC20444, VC40417, VC20417, VC20590,VC20642, VC40787, VC40642, VC30157, VC40692, VC41014, VC20468, VC40265, VC20240, VC40381, and VC40221. The VC40372 strain was outcrossed with wild-type strain N2 six times, twice in parallel to generate strains JPS428 and JPS429, which are referred to as slo-1(T381I)6x[\#1] and slo-1(T381I)6x[\#2] in the results, respectively.

Transgenesis. The background for all transgenic worms generated in this study for behavior analyses included the characterized null allele, js379, of slo-1 (Wang et al., 2001). Transgenic worms used for imaging carried the additional integrated reporter Punc-17::gfp for cholinergic neurons vsIs48 (Chase et al., 2004) and worms used for electrophysiological recordings carried the additional integrated reporter Punc-47::gfp for GABA neurons (Hammarlund et al., 2007). Multisite gateway technology (Invitrogen) was used to construct plasmids; $2501 \mathrm{~kb}$ of the native slo-1 promoter (Pslo-1) and the traditional unc-54 UTR were used in combination with either slo-1(cDNA)::mCherry or hslo(cDNA)::mCherry for wild-type transgenes. hslo cDNA was kindly provided by Dr. Richard Aldrich (University of Texas at Austin). Mutant versions were made as described below via site-directed mutagenesis. All plasmids were injected at a concentration of $20 \mathrm{ng} / \mu \mathrm{l}$. The coinjection reporter PCFJ90 at a concentration of $1.25 \mathrm{ng} / \mu \mathrm{l}$ was used to ensure proper transformation of the following arrays. Two independent isolates were obtained for each of the four strains to help control for variation in extrachromosomal arrays: strains JPS344 and JPS345 carried vxEx344[Pslo-1::slo-1::mcherry::unc54UTR,Pmyo-2::mcherry], strains JPS327 and JPS 328 carried $v x E \times 327$ [Pslo-1::slo-1(T381I)::mcherry::unc-54UTR,Pmyo-2::mcherry], strains JPS338 and JPS339 carried vxEx338[Pslo-1::hslo::mcherry::unc-54UTR, Pmyo-2::mcherry], strains JPS325 and JPS326 carried vxEx325[Pslo-1::hslo (T352I)::mcherry::unc-54UTR,Pmyo-2::mcherry]. For the control transgenic strain, the plasmid PCFJ150 (the backbone of which was used to construct the transgenic worms) was injected at a concentration of 20 $\mathrm{ng} / \mu \mathrm{l}$, along with $1.25 \mathrm{ng} / \mu \mathrm{l}$ PCFJ90 plasmid to generate strain JPS383 that carried the extrachromosomal array vxEx383[Pmyo-2::mcherry].

Site-directed mutagenesis. QuikChange II XL mutagenesis kit (Stratagene) was used. The primers $5^{\prime}$-ggacaccgaatcgtagatgatatggccacagac- $3^{\prime}$ and $5^{\prime}$-gtctgtggccatatcatctacgattcggtgtcc- $3^{\prime}$ were used to cause a $\mathrm{C} \rightarrow \mathrm{T}$ mutation in the slo- 1 gene that resulted in a T381I amino acid substitution. The primers $5^{\prime}$-gtggtctgcggacacatcattctggagagtgttt- $3^{\prime}$ and $5^{\prime}$-aaacac tctccagaatgatgtgtccgcagaccac- $3^{\prime}$ were used to cause a $\mathrm{C} \rightarrow$ T mutation in the hslo gene, which resulted in a T352I amino acid substitution. All plasmids were confirmed by sequencing the full cDNA.

Locomotion posture assay. The movement of single worms was digitally recorded at 30 frames per second for 5-10 min and analyzed as described previously (Pierce-Shimomura et al., 2008). Briefly, custom-written software automatically recognizes the worm from each frame and assigns 13 points spaced equally from the head to the tail along the midline of the body. The neck angle was defined as the angle formed by the most anterior three points for video frames selected when the head of the worm was maximally swung to the ventral side while crawling on an unseeded NGM-agar plate.

Egg-laying response to ethanol. Plastic Petri plates ( $6 \mathrm{~cm}$ diameter) filled with NGM-agar $(12 \mathrm{ml})$ were seeded with OP50 Escherichia coli at least $20 \mathrm{~h}$ before the assay and stored at $4^{\circ} \mathrm{C}$ for no more than 2 weeks. Plates were brought to room temperature $\left(20^{\circ} \mathrm{C}\right) 1 \mathrm{~h}$ before testing. Ethanol plates were prepared by adding 200 proof ethanol (Sigma Aldrich) beneath the agar $30 \mathrm{~min}$ before the assay to allow ethanol time to soak into the agar. For $600 \mathrm{~mm}$ plates, $420 \mu \mathrm{l}$ was added. For $400 \mathrm{~mm}$ plates, $292 \mu \mathrm{l}$ was added. It is important to note that these concentrations of exogenous alcohol are not equivalent to the concentration internally. Previous studies have demonstrated that internal concentrations are 40-60 mM when exposed to 400-600 mM external concentrations (Davies et al., 2003; Kapfhamer et al., 2008; Alaimo et al., 2012). The 400 mm exogenous concentration of ethanol was required to prevent a floor effect in testing egg laying in the $h s l o(+)$ transgenic worms. At the start of the assay, 10 young adult worms were placed on a control plate containing no ethanol. After $1 \mathrm{~h}$, worms were then transferred to an ethanol plate for another hour before being removed. The number of eggs laid by the 10 worms was counted on each plate. Average relative values of egg-laying frequencies per worm were determined for untreated and ethanol-treated conditions.

Locomotion response to ethanol. Plates were prepared as described in the egg-laying response to ethanol using $600 \mathrm{~mm}$ EtOH plates and seeded with $200 \mu \mathrm{l}$ of OP50. At the start of the assay, five young adult worms were placed in the center of the OP50 on a control plate containing no $\mathrm{EtOH}$ and allowed to crawl for $5 \mathrm{~min}$. Their position on the control plate was marked and worms were moved to an EtOH plate. After 20 min on the $\mathrm{EtOH}$ plate, worms were moved to another $\mathrm{EtOH}$ plate in the center of the OP50 and allowed to crawl for $5 \mathrm{~min}$. Worms were removed and their position marked. For each worm, the distance from the center was recorded as a measure of worm locomotion on control and EtOH plates.

Aldicarb analysis. Assays were performed as described previously (Mahoney et al. 2006). Briefly, 20 young adult worms were picked to plates containing unseeded, NGM-agar with either $1.5 \mathrm{~mm}$ or $2 \mathrm{~mm}$ aldicarb (Sigma). All worms were observed at the start of the assay to ensure that they were living and mobile. Every $30 \mathrm{~min}$ for the following $2 \mathrm{~h}$, the number of paralyzed worms was noted. A worm was defined as paralyzed when it showed no spontaneous movement or pharyngeal pumping.

Cell transfection. Human embryonic kidney 293 (HEK293) cells were cultured and transfected using standard procedures. Briefly, HEK293 cells were used over a passage range of 5-25. Cells were passaged every $3-5 \mathrm{~d}$ at $\sim 80 \%$ confluency using trypsin-EDTA and maintained in 25 $\mathrm{cm}^{2}$ Greiner flasks with DMEM containing 10\% fetal bovine serum, $1 \%$ GlutaMAX, $100 \mathrm{U} / \mathrm{ml}$ penicillin, and $100 \mu \mathrm{g} / \mathrm{ml}$ streptomycin in a $37^{\circ} \mathrm{C}$ incubator with $95 \%(\mathrm{v} / \mathrm{v})$ air and $5 \% \mathrm{CO}_{2}$.

For electrophysiological experiments, HEK293 cells were cultured on $13 \mathrm{~mm}$ diameter plastic Thermanox coverslips (Thermo Scientific) in a sterile 12 -well tissue culture plate until $\sim 80 \%$ confluency. Cells were transiently transfected with $50 \mathrm{ng}$ of the appropriate DNA and $10 \mu \mathrm{l}$ of PolyFect Transfection Reagent (Qiagen). cDNA of $h$ slo was contained in the mammalian expression vector pCDNA6 and kindly provided by Dr. Richard Aldrich (University of Texas at Austin). After transfection, HEK293 cells were used 24-72 h later for electrophysiological assays.

Confocal imaging. Worms were picked onto an unseeded plate and allowed to crawl for $5 \mathrm{~min}$ to remove any bacteria. Worms were then placed into a drop of NGM buffer on a glass slide containing $2 \%$ agarose and $3 \mathrm{~mm}$ azide. A coverslip was then pressed on top of the worms. All worms were used within $1 \mathrm{~h}$ of placement onto slide. Confocal images were collected using a Zeiss LSM 710 microscope at $20 \times$ and $63 \times$ magnification, and processed using ImageJ software.

Electrophysiology. For C. elegans recordings, neurons were extruded from restrained worms (L4 and young-adult stage) for patch-clamp recording as described previously (Goodman et al., 1998). Inside-out patches were obtained from ventral cord motor neurons. During recordings, electrodes and the bath contained the following (in mM): 125 potassium gluconate, $18 \mathrm{KCl}, 4 \mathrm{NaCl}, 0.7 \mathrm{CaCl}_{2}, 1 \mathrm{MgCl}_{2}, 10 \mathrm{EGTA}$, and 10 
HEPES; pH 7.2, adjusted with $\mathrm{KOH}$ for a symmetrical potassium environment during single-channel recordings.

For HEK293 cells, single-channel recordings were obtained from inside-out membrane patches using standard procedures. The high- $\mathrm{K}^{+}$ extracellular recording solution contained the following (in $\mathrm{mM}$ ): 140 $\mathrm{K}^{+}$gluconate, $2.2 \mathrm{CaCl}_{2}$, 4 EGTA, 4 HEDTA, $1 \mathrm{MgCl}_{2}$, and 15 HEPES. The $1 \mu \mathrm{M}$ calcium intracellular recording solution contained the following (in $\mathrm{mM}$ ): $140 \mathrm{~K}^{+}$gluconate, $5 \mathrm{Na}^{+}$gluconate, $0.43 \mathrm{CaCl}_{2}, 2$ HEDTA, $1 \mathrm{MgCl}_{2}$, and 15 HEPES. Solutions were adjusted to $\mathrm{pH} 7.35$ with $\mathrm{KOH}$ as needed. These solutions were used previously by Yuan et al. (2008) to study effects of alcohol on the BK channel.

Single-channel currents were low-pass filtered at $2.9 \mathrm{kHz}$ and digitized at $10 \mathrm{kHz}$ using an EPC10 amplifier and Patchmaster software (HEKA Elektronik). Data were stored on a PC and analyzed using QuB (Milescu et al., 2000).

Statistical analysis. Data that passed Shapiro-Wilk normality test were analyzed using standard $t$ or ANOVA tests and the Holm-Sidak method for post hoc multiple-comparison test (Zar, 1999). Data that did not pass the Shapiro-Wilk normality test were analyzed using the Mann-Whitney rank sum test or Kruskal-Wallis ANOVA on ranks and Dunn's test for post hoc multiple comparisons (Zar, 1999).

\section{Results \\ T381I missense mutation in the SLO-1 BK channel dramatically reduces ethanol intoxication without altering other BK channel-dependent behaviors}

To elucidate residues of the BK channel that are selective for behavioral intoxication by ethanol but not basal function, we screened all mutant strains harboring missense mutations in the slo-1 gene from the C. elegans Million Mutation Project (Thompson et al., 2013). This library contains 32 strains with unique missense mutations in the slo-1 gene (Fig. 1A). Intoxication was measured by the degree that ethanol inhibited egg laying behavior.

Most mutations in these strains were associated with wildtype-like sensitivity to intoxication, including VC20444 (L720F) and VC40804 (D401N; Fig. 1A, blue-coded residues). We defined wild-type sensitivity to ethanol as $\leq 41 \%$ of egg laying for ethanol compared with control conditions, which was the reduction in egg laying on ethanol (19\%) plus two SDs (11\%) demonstrated by wild-type C. elegans (Fig. 2). Low level of resistance was defined as $42-61 \%$, moderate resistance $62-82 \%$, and high resistance $>82 \%$. One strain, VC20240, with missense mutation G1036D, displayed moderate resistance to intoxication (Figs. 1A, $2 A, B)$. A few strains could not be assessed because they displayed basal defects in egg laying (Fig. 1A). Defective egg laying in these strains may be due to gain-of-function mutations in the slo-1 gene as observed previously (Davies et al., 2003), due to background mutations, or due to both.

Of all of the missense mutants, however, only one strain, VC40372 (T381I), which harbors the slo-1 allele gk602291, displayed strong resistance to intoxication (Fig. $1 A-C$, red bold text). Similar to the slo-1 (null) mutant, VC40372 mutant worms showed only a $6.3 \%$ reduction in egg laying (Fig. $2 A, B$ ). In contrast, ethanol reduced the rate of egg laying by $80.7 \%$ in wild-type worms (Fig. 2A,B). The gk602291 allele results in a threonine to isoleucine mutation at position 381 of the worm SLO-1 channel. This is located only 10 and 15 residues away from the predicted calcium-binding aspartate residues in the RCK1 domain on the intracellular tail (Fig. 1A-C). Importantly, the T381 residue is highly conserved across species (Fig. 1B).

The strong ethanol resistance of VC40372 may be due to additional background mutations or solely due to the $g k 602291$ mutation in the slo- 1 gene. To test the first possibility, we outcrossed the VC40372 strain six times, twice independently, with wild-type by tracking the gk602291 genotype to generate strains
slo-1(T381I)x6[\#1] and slo-1(T381I)x6[\#2]. Both of the outcrossed strains retained a strong level of resistance to ethanol that was statistically indistinguishable from the slo-1 (null) strain (Fig. $2 C)$. In addition, because background mutations have been known to persist after outcrossing, we asked whether one of the $\times 6$ outcrossed strains retained resistance after crossing with the slo-1(null) strain. We found that the F1 progeny from this cross, slo-1(T381I)x6[\#2]/slo-1(null), displayed strong resistance to ethanol equivalent to the parent strains, a phenomenon called "failing to complement" (Fig. 2C). This provides strong evidence that the ethanol resistance of the VC40372 strain resulted from the gk602291 mutation in slo-1, since recessive background mutations in the parental strains would be heterozygous in the F1 cross progeny and fail to account for ethanol resistance.

We performed additional complementation testing with wildtype worms to uncover the genetic relation between the null and T381I slo-1 alleles. The F1 cross progeny of slo-1 (null) and wildtype displayed intoxication indistinguishable from wild-type (Fig. 2C). This shows that only one wild-type copy of the slo-1 gene is needed to rescue slo-1-dependent intoxication. Intriguingly, we found that the F1 cross progeny of slo-1(T381I)x6[\#2] and wild-type displayed an ethanol sensitivity intermediate between wild-type and slo-1(null) strains (Fig. 2C). Given that BK channels are composed of four subunits (Shen et al., 1994), this result hints at the possibility that the mutant SLO-1(T381I) channel $\alpha$-subunits may form heteromers with wild-type $\alpha$-subunits, resulting in a channel with intermediate ethanol sensitivity in vivo.

To test whether the T381I mutation conferred resistance to a distinct ethanol-mediated behavior, we tested the two $6 \times$ outcrossed slo-1(T381I) strains for resistance to the depressing effects of ethanol on locomotion. Both strains exhibited resistance to intoxication ( $\sim 62 \%$ of untreated level), crawling further away from a starting point than wild-type, but similar to the slo-1 (null) mutant worms (70\% of untreated level; Fig. 2D). In contrast, ethanol significantly reduced the rate of locomotion in wild-type worms (29\% of untreated level; Fig. 2D) in agreement with our previous findings (Davies et al., 2003). This suggests that the T381I mutation provides resistance to ethanol in distinct neuromuscular circuits in C. elegans. Our results above suggest that the T381I missense allele gk602291 was the sole determinant, explaining the robust resistance to intoxication in slo-1 mutant strains carrying the T381I mutation.

To determine whether the mutation compromises basal function, leading to lack of ethanol sensitivity, we assessed BK channel function in vivo by analyzing three independent behaviors previously found to depend on normal BK-channel function: neck posture, egg laying, and aldicarb paralysis.

Mutations in slo- 1 that are predicted to eliminate or strongly reduce BK channel function cause C. elegans to crawl with unusually sharp head bends-a phenotype described as a "crooked neck" posture (Kim et al., 2009). We performed quantitative image analysis on the slo-1(T381I) x6 mutants to compare neck posture with wild-type and the slo-1(null) mutant. Similar to other mutants tested with wild-type sensitivity or moderate resistance to intoxication, the slo-1 (T381I) mutant displayed wild-type neck posture consistent with functional BK channels in vivo (Fig. 3A). Unlike previously characterized slo-1 null and loss-of-function alleles, slo1(T381I) represents the first mutant that is both strongly resistant to ethanol while displaying wild-type neck posture.

We next investigated basal egg-laying behavior, which was previously shown to be slightly lower in slo-1(null) than in wild-type worms (Davies et al., 2003). Here, we also found a slight but significant difference between slo-1(null) and wild-type egg-laying rates 
SLO-1 BK Channel $\alpha$ subunit Protein

MGEIYSPSQSKGENQPYGYPMNCNLSRVFMEMTEEDRKCLEERKYWCFLLSSITTFCASM 60 ILVVIWRVVTHLCCQRREKEFVEPIPAPEAVQINMNGSKHAPSETDPFLKQQEEKHLGWM 120 TEAKDWAGELISGQSLTGRFLVLLVF ILSIGSLI IYFYDASFQNFQVETCIPWQDSPSQQ 180 IDLGFNIFFLVYFFIRFIAASDKVWFLLEMYSWIDFFTIPPSFVAIYLQRNWLGFRFLRA 240 LRLMTVPDILQYLNILKTSSS IRLTQLVTIFVAVCLTGAGLVHLLENSGDFFKGFINPHR 300 ITYADSVYFVLVTMSTVGYGDIYCTTLCGRLFMIFFILFGLAMFASYVPEIADLIGNRQK 360 YGGEYKGEHGKKH IVVCGHITYDSVSHFLQDFLHEDRDDVDVEVVFLHRVVPDLELEGLF 420 KRHFTKVEFFTGTVMD SLDLSRVKIGDADACLVLANKYSTNPDAEDAANIMRVISIKNYS 480 SDIRVIVQLMQYHNKAYLLNI PSWDWKRGDDVICLAELKLGFIAQSCLAPGFSTMMANLF 540 AMRSFKTSQTTPDWLNLYLCGAGMEMYTDTLSHSFVGMTFPEAVDLLFNRLGLLLLAIEL 600 KDEENKECNIAINPGPHIVIQPQTQGFFIAQSADEVKRAFFWCKQCHDDIKDVSLIKKCK 660 CKNLALFRRNTKHSTAARARATDVLQQFQPQAPAGPMGHLGQQVQLRMINQQSSTSDTHL 720 NTKSLRFAYEIKKLMP SSGGRRNSMS I PPDGRGVDFSKDFEQQFQDMKYDSTGMFHWCPS 780 RNLEDCVLERHQAAMTVLNGHVVVCLFADQDSPLIGLRNF IMPLRSSNFHYHELKHVVIV 840 GDLEYLRKEWKTLYNLPKISILNGSPLSRADLRAVNINLCDMCVIISARVPNTEDTTLAD 900 KEAILAS LNIKAMQFDDTLGF FPMRHQTGDRSPLGSPISMQKKGAKFGTNVPMITELVND 960 SNVQFLDQDDDDDPDTELYLTQPFACGTAFAISVLDSLMSTTYFNDSALTLIRTLVTGGA 1020 TPELELILAEGAGLRGGYSTPETLSNRDRCRIAQISLQDNPYDGVVHNTTYGAMFTIALR 1080 RYGQLCIGLYRLHDQDNPDSMKRYVITNPPAELRIKNTDYVYVLEQFDPGLEYEPGKRHF 1140

\begin{tabular}{|c|c|c|c|c|c|c|c|c|}
\hline Mutation & Strain & $\begin{array}{c}\text { EtOH } \\
\text { response }\end{array}$ & Mutation & Strain & $\begin{array}{c}\text { EtOH } \\
\text { response }\end{array}$ & Mutation & Strain & $\begin{array}{c}\text { EtOH } \\
\text { response }\end{array}$ \\
\hline S6P & VC40853 & Sensitive & D436E & VC40468 & Sensitive & E789K & VC40787 & Sensitive \\
\hline P102S & VC40064 & $\mathrm{N} / \mathrm{A}$ & P462L & VC40143 & Sensitive & R818Q & VC40642 & Sensitive \\
\hline S103N & VC40938 & Sensitive & P462S & VC40062 & Sensitive & S936A & VC30157 & Sensitive \\
\hline F140L & VC30161 & Sensitive & G563E & VC20545 & $N / A$ & D975G & VC40692 & Sensitive \\
\hline P177L & VC40899 & Sensitive & L595F & VC40416 & Sensitive & T988I & VC41014 & $\mathrm{N} / \mathrm{A}$ \\
\hline G234E & VC40774 & Sensitive & $\mathrm{R} 669 \mathrm{H}$ & VC20244 & Sensitive & T1001I & VC20468 & Sensitive \\
\hline A304T & VC40641 & Sensitive & L720F & VC20444 & Sensitive & A1008V, & VC40265 & $\mathrm{N} / \mathrm{A}$ \\
\hline M333L & VC40384 & $\mathrm{N} / \mathrm{A}$ & Y729F & VC40417 & Sensitive & & & \\
\hline T381I & VC40372 & $\begin{array}{l}\text { Strongly } \\
\text { Resistant }\end{array}$ & G753S & VC20417 & Sensitive & G1036D & VC20240 & $\begin{array}{c}\text { Moderately } \\
\text { Resistant }\end{array}$ \\
\hline D401N & VC40804 & Sensitive & G753D & VC20590 & Sensitive & L1044F & VC40381 & Sensitive \\
\hline $\mathrm{D} 436 \mathrm{~N}$ & VC40392 & Sensitive & G753S & VC20642 & $N / A$ & D1096N & VC40221 & Sensitive \\
\hline
\end{tabular}

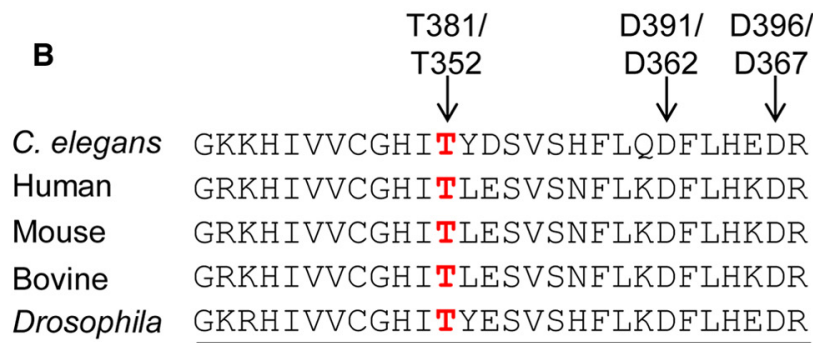

RCK1
C

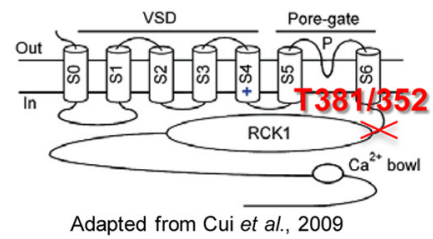

Figure 1. Primary sequence of BK channel and ethanol sensitivity of missense mutants. $A$, SLO-1 $\alpha$-subunit protein with residues color coded based on C. elegans strains with unique missense mutants available from Million Mutant Library (blue, EtOH sensitive; green, not tested; and red, resistant to ethanol). Aspartate residues in the RCK1 domain and calcium bowl critical for calcium sensing are underlined. Mutant strains cataloged below with predicted missense mutation and behavioral sensitivity to ethanol. Strains defective in basal egg laying were not tested (N/A). Sensitivity to intoxication was determined by relative egg-laying behavior before and during ethanol treatment. Strain VC 40372 contains a mutation in conserved threonine residue 381 and was the only missense mutant tested that displayed strong resistance to intoxication. B. The T381 residue in SL0-1 is conserved from worm to human and is equivalent to the mouse T352 position. For simplicity, this residue will be referred to as the T352 residue when referring to the human BK channel in this article. This residue is located 10 and 15 residues away from the underlined calcium-sensing aspartate residues in the RCK1 domain. C, Diagram of SL0-1 $\alpha$-subunit with location of T381 residue in relation to transmembrane and calcium-binding domains (arrows). Adapted from Cui et al., 2009. 


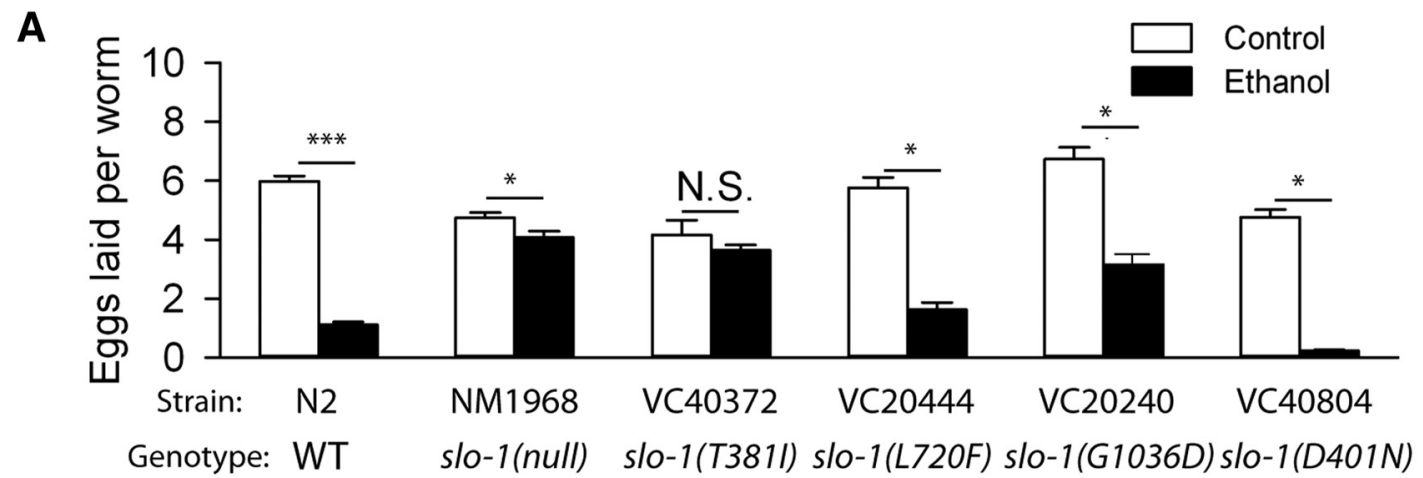

B
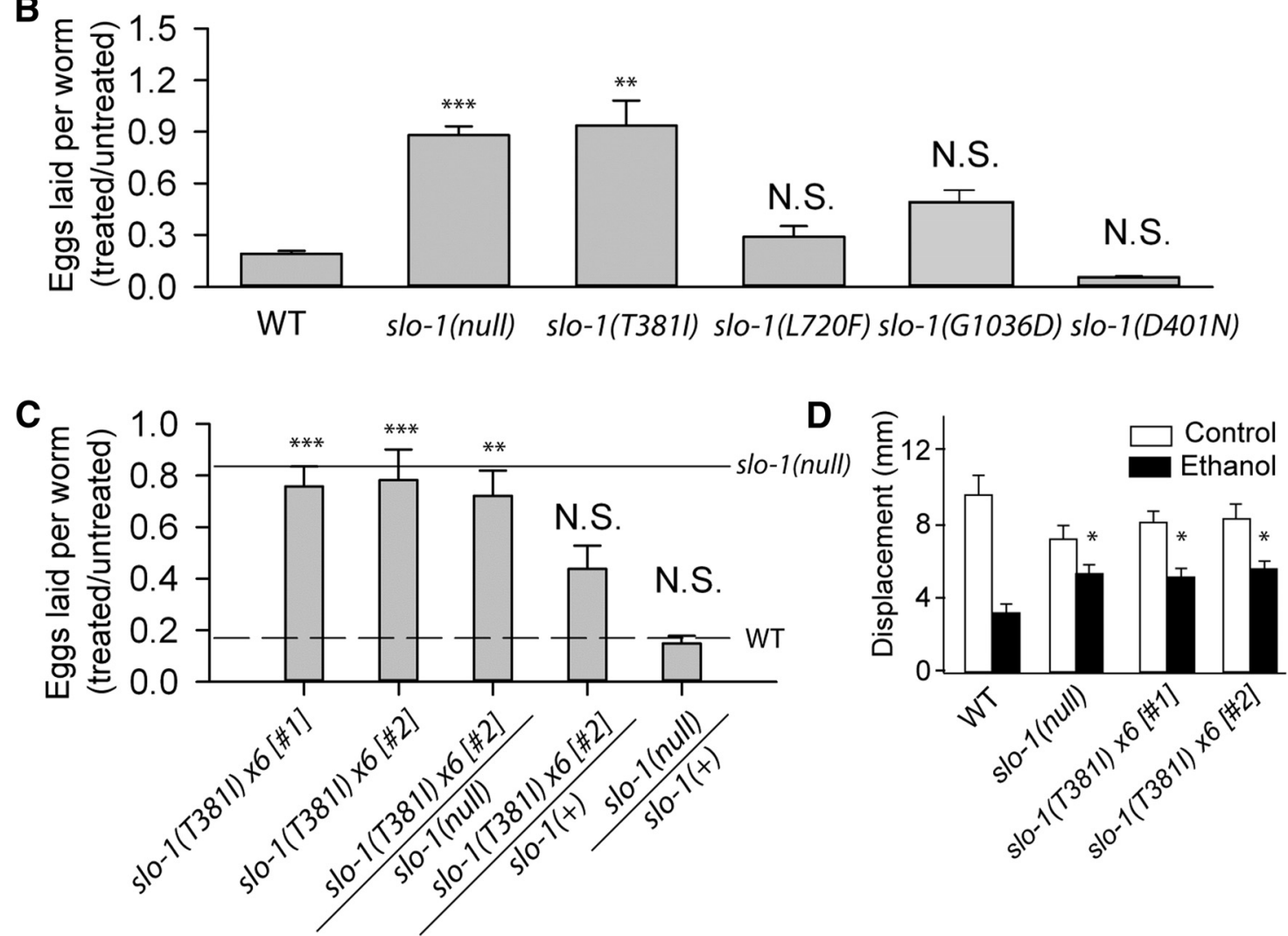

Figure 2. T381I mutation in the SL0-1 channel confers strong resistance to intoxication in C. elegans. $A$, Intoxication sensitivity as determined by egg laying on control versus ethanol plates for various strains: wild-type (WT) strain N2 (N=41), slo-1 (null) strain NM1968 (N=30), VC40372 (N=5), VC20444 (N=3), VC20240 (N=6), and VC40804 (N=3) where N represents an assay with 10 worms each. VC40372 was the only strain that displayed strong resistance to intoxication. $\boldsymbol{B}$, Intoxication as determined by relative egg-laying sensitivity to ethanol in the strains in $\boldsymbol{A}$. The slo-1(T381I) and slo-1 (null) mutants were significantly less intoxicated than WT. Other missense mutants did not display strong resistance. C, Intoxication as determined by relative egg-laying sensitivity to ethanol in strains derived from outcrossed $s / 0-1$ (T381) or s $/ 0-1$ (null) parents. Horizontal lines indicate behavior of $5 / 0-1$ (null) and WT worms. After independently outcrossing six times, the two resulting slo-1(T381) $\times 6$ mutants $(N=14, N=9$, respectively) displayed strong resistance to intoxication comparable to slo-1(null). Strain slo-1(T3811)x6[\#2] failed to genetically complement $\operatorname{slo-1}($ null $)(N=9)$, indicating that T381l is associated with ethanol resistance. One WT copy of $s / 0-1(+)$ was sufficient to rescue intoxication when crossed with slo-1 (null) $(N=9)$. Intermediate ethanol sensitivity was displayed by a strain heterozygous for the T381I mutation and a WT copy of $s / 0-1(N=6)$. D, Locomotion on control and ethanol plates for WT, slo-1(null), and slo-1(T3811)x6 mutants ( $n=30$ each). On ethanol, slo-1(null) and slo-1(T381) $\times 6$ mutants were significantly more displaced from the start location than WT $\left({ }^{*} p<0.05\right)$. Error bars represent SEM.

(Fig. 3B). However, no difference was observed between slo1(T381I)x6 outcrossed strains and wild-type, providing further evidence for functional BK channels in the mutants (Fig. 3B).

The BK channel is also an important negative regulator of neurotransmitter release at the neuromuscular junction in $C$. elegans (Wang et al., 2001). One manifestation of this is that loss of slo-1 function causes hypersensitivity to paralysis by the acetylcholinesterase inhibitor, aldicarb, due to abnormally rapid buildup of acetylcholine at the neuromuscular junction. Thus, chronic exposure to aldicarb causes a gradual paralyzing contraction of muscles that occurs faster in slo-1(null) relative to wild-type
(Wang et al., 2001; Davies et al., 2003). In this study, we tested aldicarb sensitivity of the slo-1(T381I)x6[\#2] mutant and found that it was more like wild-type than slo-1(null) for both 1.5 and 2 $\mathrm{mm}$ aldicarb treatments (Fig. 3C). Overall, our results strongly suggest that the worm BK channel with the T381I missense mutation is both functional in vivo and resistant to ethanol.

Single conserved residue required for ethanol sensitivity of the human BK channel

We performed an additional test to determine whether the T381I missense mutation results in an ethanol-resistant, but functional 
A

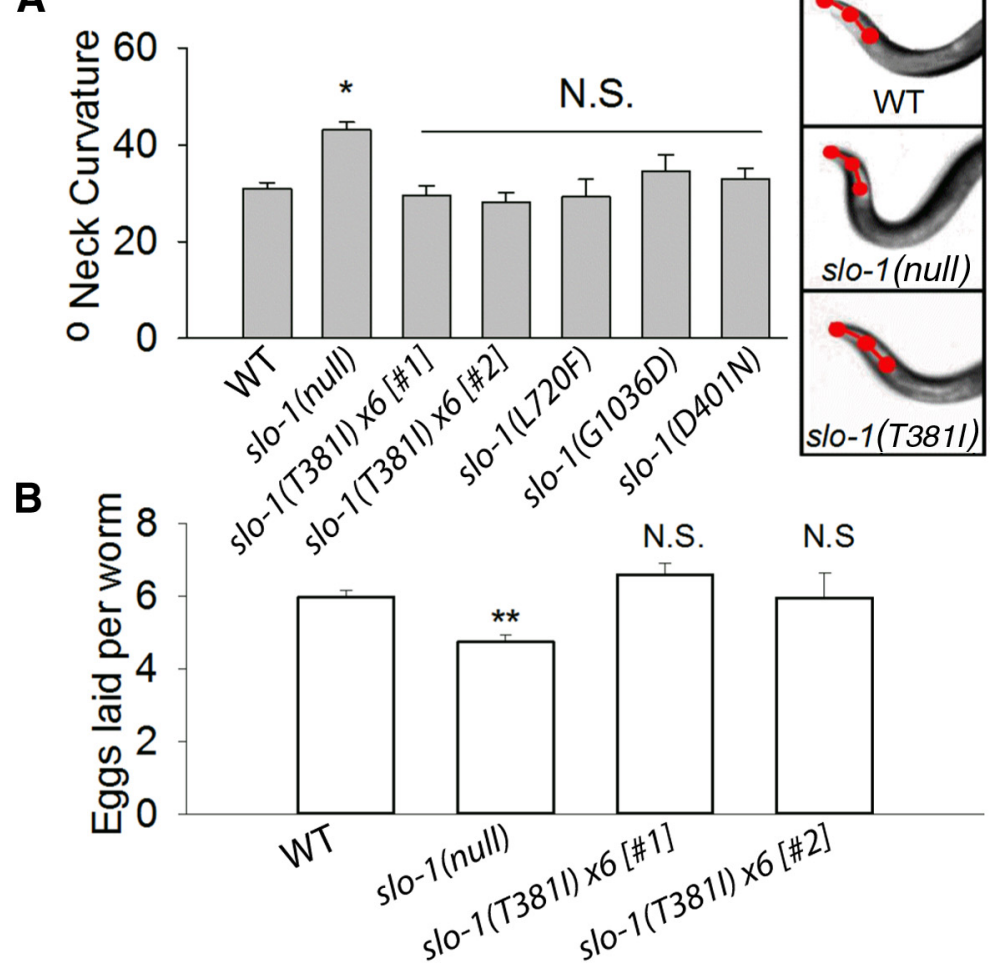

Aldicarb $1.5 \mathrm{mM}$
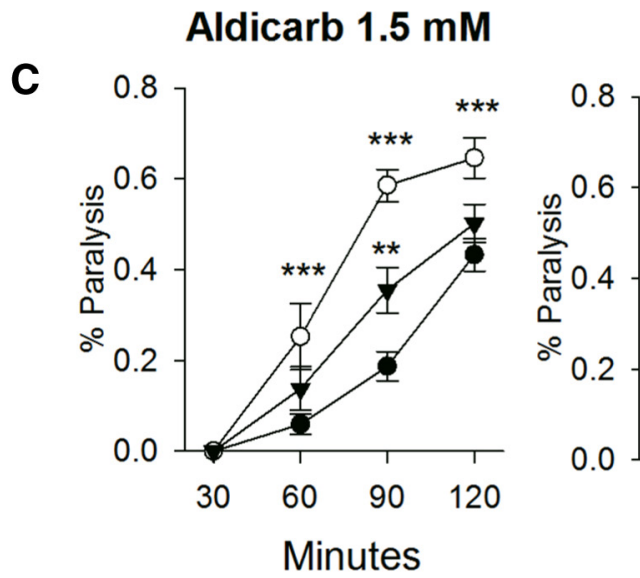

Aldicarb $2 \mathrm{mM}$

Figure 3. T381I SL0-1 mutation has little or no effect on three ethanol-independent BK channel-mediated behaviors. $A$, Neck curvature is sharper in slo-1 (null) mutants $(n=50)$ than in wild-type (WT) worms $(n=36)$. Both slo-1(T381) $x 6$ strains $(n=17$ each) display WT neck posture ( $p=0.99$ for each), as do other missense mutants Representative images of neck posture of WT and mutant worms are shown on the right. $\boldsymbol{B}$, In the absence of ethanol, egg laying is slightly, but significantly, lower in slo-1 (null) versus WT worms ( $N>30$ each, $p<0.05$ ). In contrast, both s/0-1(T3811) $x 6$ strains display WT rates of egg laying $(N>$ 9 each, $p=0.99)$. N represents an assay with 10 worms. $C$, Aldicarb $(1.5 \mathrm{~mm})$ paralyzes s $/ 0-1$ (null) mutants $(N=8)$ significantly faster than slo-1(T381) X6\#2 $(N=7, p<0.001)$ and WT $(N=9)$ worms $(N=9, p<0.001)$. Post hoc analysis shows that slo-1(T3811)x6\#2 worms were paralyzed slightly but significantly more than WT at the 90 min time point only $(p<0.05)$. With $2 \mathrm{~mm}$ aldicarb, slo-1(null) worms $(N=6)$ were significantly more paralyzed than both WT $(N=7, p<0.001)$ and slo-1(null) $x 6[\# 2]$ strains $(N=4, p<0.001)$. N represents an assay with 20 worms. Error bars represent SEM.

ethanol sensitivity (Fig. 4A1) and neck posture (Fig. 4B1). In contrast, transformation with the slo-1(T381I) transgene rescued neck posture, but failed to rescue ethanol sensitivity (Fig. 4A1,B1). Identical results were found for independently derived transformant strains (\#1 and \#2), suggesting that these results were not due to transgenesis efficiency. In addition, a control strain that was transformed with only the coinjection marker and empty plasmid failed to rescue ethanol sensitivity or neck posture (Fig. 4A1,B1, None). These results provide strong independent evidence that the T381I mutant SLO-1 channel functions normally in vivo in addition to being insensitive to ethanol.

The T381 residue of SLO-1 is conserved across a wide range of species, including in the human BK channel (Fig. 1B). To determine whether this residue plays a conserved role in behavioral responses to ethanol, we transformed slo-1(null) mutants with wild-type or mutant cDNA for the human BK channel gene hslo. For the mutant, the equivalent T352 residue was mutated to encode isoleucine. As above, we used the Pslo-1 promoter and tagged the human BK channel at the $\mathrm{C}$ terminus with mCherry and cotransformed with the same fluorescent reporter. Consistent with our results with the worm slo-1 $(+)$ transgene, we found that the wild-type human $h$ slo $(+)$ transgene rescued ethanol sensitivity and neck posture for two transformant strains (Fig. 4A2,B2). Also consistent with our results in slo-1, we found that transformation with hslo(T352I) selectively rescued the neck posture phenotype but not ethanol sensitivity (Fig. 4A2,B2). In addition, a control strain that was transformed with only the coinjection marker and empty plasmid failed to rescue ethanol sensitivity or neck posture (Fig. 4A2,B2). This suggests a strong conservation from worm to human of the threonine $381 / 352$ residue in contributing to behavioral intoxication by ethanol, without being critical for channel function.

The worm T381I and human T352I mutant BK channels might convey resistance to ethanol and yet rescue neck posture if they are expressed at abnormally low levels and/or are expressed in cells important for neck bending but not for intoxica-

BK channel in vivo. We transformed the slo-1(null) strain with wild-type or T381I mutant cDNA for the slo-1 isoform slo-1a. To visualize SLO-1 protein expression in the worm, we tagged the C-terminal (intracellular) side of SLO-1 with the fluorophore mCherry. The slo-1a::mCherry transgene was driven by the native slo-1 promoter Pslo-1. Transgenic worms harboring the wildtype or mutant slo-1 transgene were identifiable as worms that also expressed a cotransformed mCherry reporter in the feeding organ (pharynx). The wild-type slo-1 $(+)$ transgene rescued both tion. To address these possibilities, we examined the in vivo distribution of BK channels by visualizing their mCherry tag in the transgenic strains described above. Despite the widespread neuronal and muscle BK expression profile, expression of wildtype slo- 1 in cholinergic neurons alone was previously found to be sufficient to rescue intoxication (Davies et al., 2003). Thus, we used a cholinergic GFP reporter to assess colocalization of mCherry-tagged transgenic BK channels in cholinergic neurons. By confocal microscopy, we found colocalization of mCherry 
A1

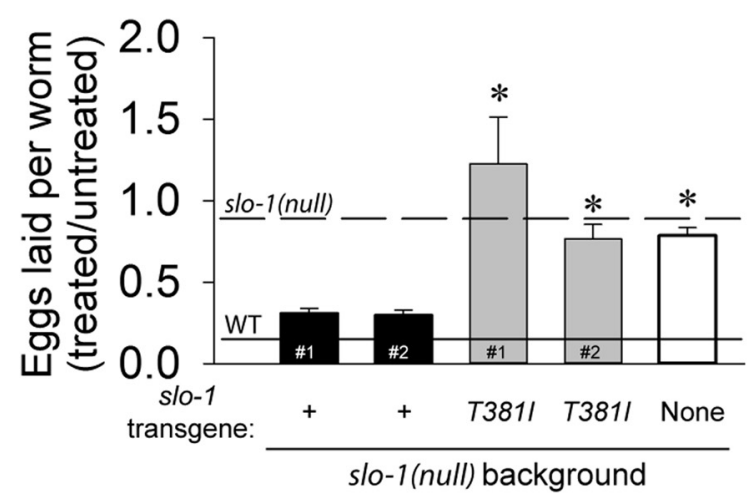

B1

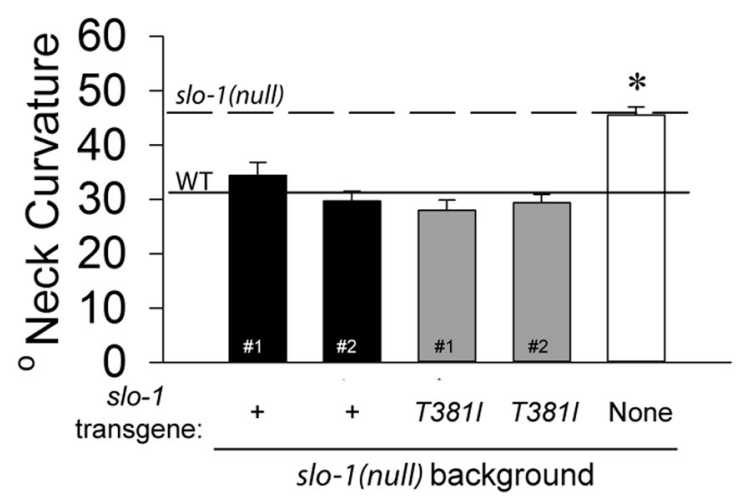

A2

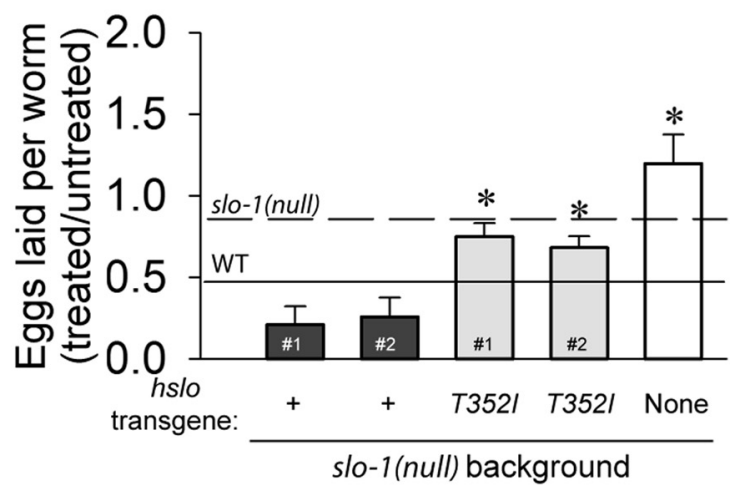

B2

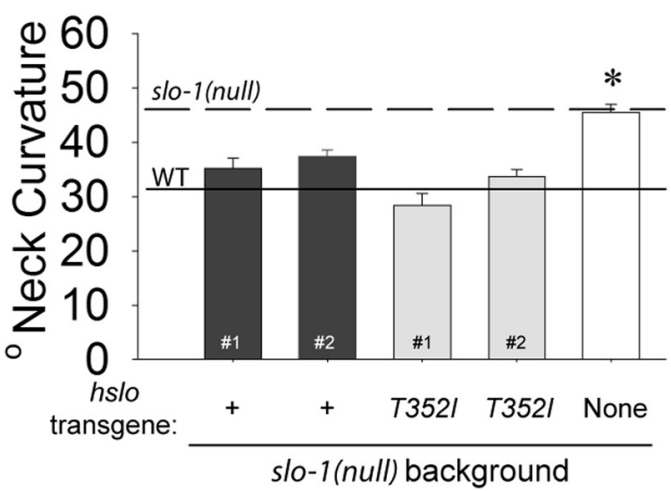

Figure 4. Transgenic expression of T381I worm or T352I human BK channels selectively rescues neck curvature but not intoxication in the s/0-1(null) mutant. $\boldsymbol{A}$, Expression of wild-type (WT) slo- $1(+)$ rescues intoxication $(\boldsymbol{A} 1 ; \mathrm{N}=6$ for each genotype) and neck curvature $(\boldsymbol{A} 2 ; n>14$ for each genotype) in the slo-1 (null) mutant for two independent strains. Expression of slo-1(T382I) mutant channel fails to rescue intoxication ( $\boldsymbol{A} 1, p<0.05$ for both), but succeeds in rescuing neck curvature (A2) in the s/o-1 (null) mutant for two independent strains. $\boldsymbol{B}$, Likewise, expression of WT human channel $h \mathrm{hlo}(+)$ in slo-1 (null) mutant rescues both intoxication $(\boldsymbol{B} 1 ; N=6$ for each genotype) and neck curvature (B2; $n>26$ for each genotype) for two independent strains. Expression of the $h$ slo(T352l) mutant BK channel fails to rescue intoxication for two strains ( $\boldsymbol{B} 1, p<0.01, p<0.05$, respectively, $N=6$ each) but succeeds in rescuing neck curvature (B2). In all graphs, the control transgenic strain with fluorescent reporter fails to rescue either behavior ( $n=6-33$ ). Horizontal lines indicate levels for slo-1 (null) and WT strains. N represents an assay with 10 worms. Error bars represent SEM.

signal in cholinergic motor neurons regardless of whether the transgenic BK channel was wild-type or mutant, worm or human (Fig. 5). Coexpression could be seen at high magnification $(63 \times)$ in somata and neuronal processes throughout the ventral nerve cord across all strains (Fig. 5, column 5). These results are also consistent with the reported expression pattern of the Pslo-1 promoter that was used to drive the transgenes (Chen et al. 2011). Importantly, punctate mCherry fluorescence was colocalized with GFP throughout the cholinergic motor neurons previously shown to be critical for the behavioral response to ethanol (Fig. 5 ). Thus, gross differences in expression pattern or in expression level do not appear to explain the dramatic ethanol resistance in the worm T381I or human T352I transgenic strains. Instead, our results strongly suggest that these mutations specifically affect the interaction between ethanol and the BK channel in vivo.

The T352I mutation selectively eliminates ethanol sensitivity of the BK channel

The behavioral and expression analyses described above suggest that the T352I mutant BK channel functions normally in C. elegans. For a direct measure of channel function, we performed in vivo single-channel patch-clamp recordings of identified neurons in slo-1(null) mutant worms that had been transformed with wild-type or T352I mutant human BK channels. Our previous work demonstrated that SLO-1 single-channel currents were completely absent in neurons of slo-1(null) mutants (Davies et al., 2003). In contrast, we found a high incidence of large conductance, outward rectifying currents with inside-out recordings from ventral cord motor neurons in worms expressing the wildtype or T352I mutant HSLO channel (Fig. 6). These currents are likely mediated by the HSLO channel because they had a conductance of $292 \pm 2$ SEM pS $(n=4)$. This value is consistent with previous reports of the human channel, which are notably higher than the 38 pS conductance of the worm SLO-1 channel (Dworetzky et al., 1994; Davies et al., 2003). In addition, these currents were blocked by the BK channel-selective antagonist paxilline, and were voltage and calcium sensitive. These findings demonstrate functional human BK channels expressed in C. elegans neurons and indicate that the T352I mutation does not overtly affect single-channel expression or in vivo function.

To quantitatively measure effects of the T352I mutation, we next studied HSLO channels transfected into HEK cells. Under basal conditions, no significant differences in conductance were observed between the wild-type and T352I mutant HSLO channel (Fig. 7A), and only minor differences in open probability were seen across different voltages (Fig. $7 B$ ). ANOVA showed a small yet significant difference in the interaction between genotype and voltage $(p=0.045)$, but no significant difference was found in post hoc analyses comparing channel open-probability values at specific voltages $(40 \mathrm{mV} p=0.5,50 \mathrm{mV} p=0.19,60 \mathrm{mV} p=0.12$, 


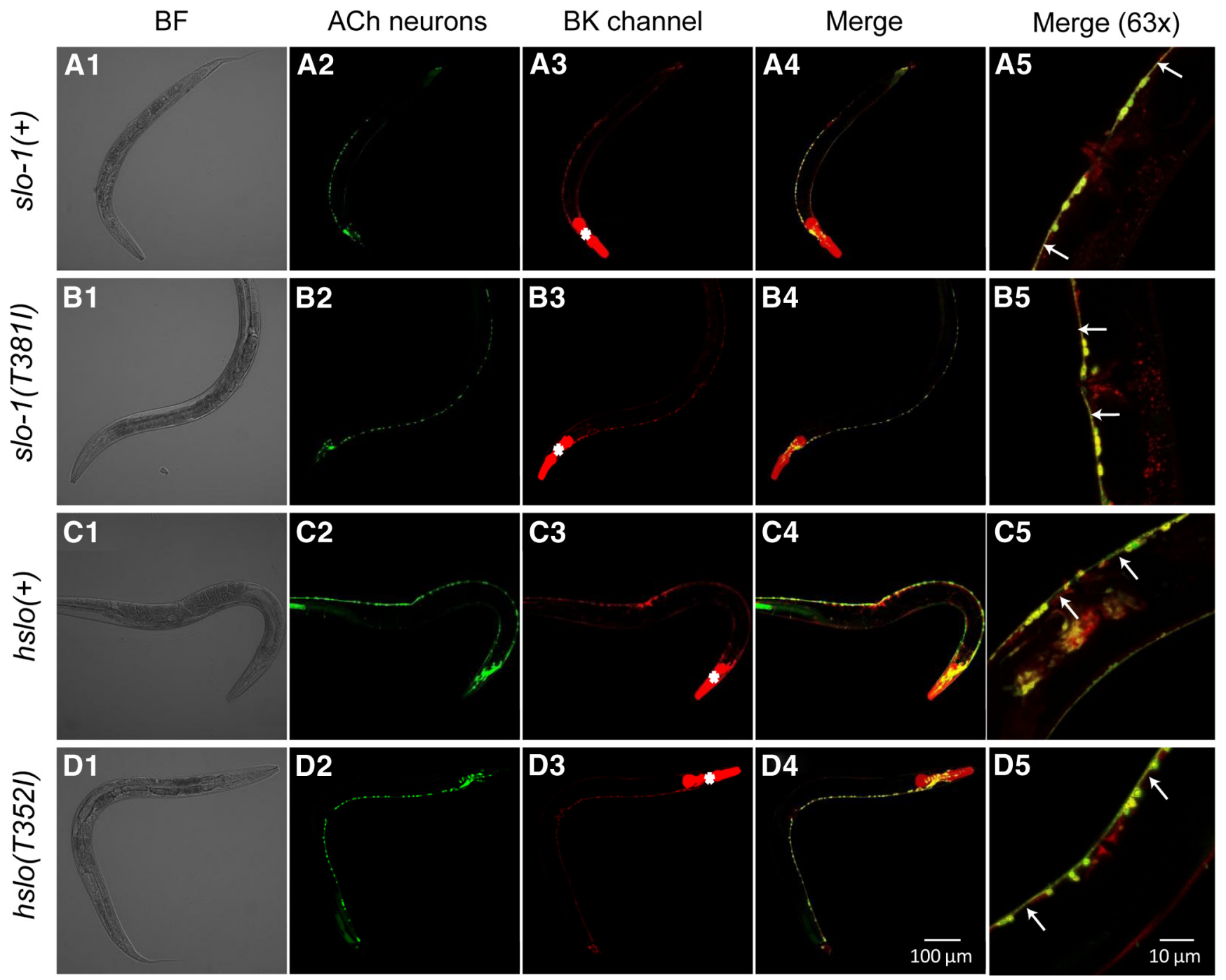

Figure 5. Visualization of transgenic BK channels in vivo. Each row shows photomicrographs of a representative worm expressing different BK channels tagged with $\mathrm{mCherry} \mathrm{on} \mathrm{a} \mathrm{s/o-1(null)}$ background. Bright-field (BF) images of individual worms displayed in column 1. Acetylcholine (ACh) neurons are labeled in all worms via a Punc-17::gfp fluorescent reporter in column 2. In all four transgenic strains, mCherry-tagged BK channels are observed in column 3 throughout the ventral nerve cord and tail neurons, matching previous expression profiles for the BK channel. Gross differences were not observed in expression level or pattern among the four transgenic strains. White asterisks indicate mCherry cotransformation marker expressed in the anterior feeding organ (pharynx). In addition, for all four strains mCherry colocalizes with green cholinergic neurons in column 4 as well as in representative magnified images at $63 \times$ in column 5 . White arrows mark colocalization in neuronal processes. Letters A-D represent different strains. Numbers 1-5 represent different views. Scale bars: columns 1-4, $100 \mu \mathrm{m}$; column 5, $10 \mu \mathrm{m}$.

A

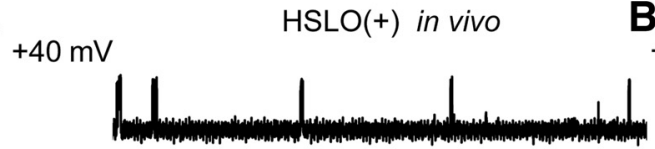

B $+40 \mathrm{mV}$

$+50 \mathrm{mV}$

$+50 \mathrm{mV}$

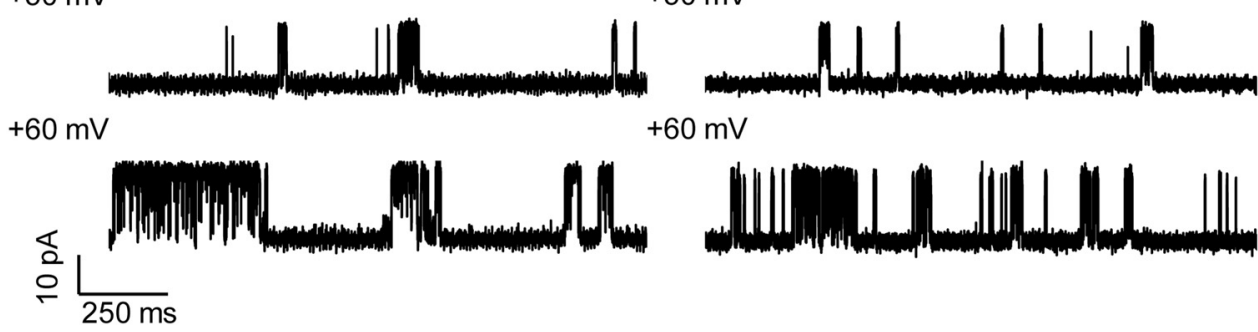

Figure 6. HSLO(T352l) mutant currents qualitatively resemble HSLO wild-type currents in vivo in a slo-1 (null) background. $A$, Representative single-channel patch-clamp recordings from ventral motor cord neurons revealed large amplitude (292 pS), outward rectifying potassium currents characteristic of wild-type human BK channels. B, Representative recordings of HSLO(T352I) mutant channel resembles those of the wild-type HSLO channel in worm neurons. 



Figure 7. T352I mutant human BK channel displays only minimal changes in basal function from wild-type in vitro. Single-channel BK currents were studied in a symmetrical $\mathrm{K}^{+}$saline solution in patches from HEK cells injected with either WT or T352I mutant BK channel CDNA. $A$, Reversal potential ( $-1.4 \mathrm{mV}$ WT and $-1.37 \mathrm{mV}$ T352l) and conductance were the same for both channels ( $n=7$ for both, $p=0.17$ ). $\boldsymbol{B}$, Analyzing opening probability at three holding potentials ( $n=10 \mathrm{WT}, n=8 \mathrm{~T} 352 \mathrm{l})$ revealed a slight, yet significant effect of the T352I mutation compared with WT BK channel $(p<0.05)$. However, post hoc tests did not reveal differences at any voltages tested ( $40 \mathrm{mV} p=0.5,50 \mathrm{mV} p=0.19,60 \mathrm{mV} p=0.12$ ). Error bars represent SEM.

$n=10)$. These results demonstrate that the T352I mutation has only subtle effects on basal function of the human BK channel at the level of single-channel currents.

We next tested effects of the T352I mutation on ethanol responses of HSLO in HEK cells. Previous work has demonstrated that ethanol modulates single-channel currents from BK channels excised from neuronal membranes or minimal planar lipid bilayers, suggesting a direct interaction of the BK channel and ethanol (Chu et al., 1998). Consistent with these reports for the wild-type human BK channel, we found that ethanol application caused a significant increase in open probability of $50-80 \%$ above basal levels $(40 \mathrm{mV}$ holding potential; Fig. $8 A, C$ ). This increase had a rapid onset and was reversible upon removal of ethanol (Fig. $8 A 1, A 2, C$ ). In contrast, ethanol had no effect on the T352I mutant BK channel at this holding potential (Fig. 8A1,A2,D).

The mutant also showed a slight, but insignificant difference in open probability at $40 \mathrm{mV}\left(\mathrm{P}_{\mathrm{o}} \mathrm{WT}=0.22\right.$ vs $\left.\mathrm{T} 352 \mathrm{I}=0.15\right)$. Such a change might lower the activation state of the mutant channel and prevent potentiation by ethanol. To compensate for subtle differences in activation and observe channel function under similar activation conditions, we compared the ethanol response of the mutant at $50 \mathrm{mV}$ to the wild-type channel at $40 \mathrm{mV}$ (basal $\mathrm{P}_{\mathrm{o}} \mathrm{WT}=0.22$ vs T352I $=0.26$ ). After 2 min of ethanol application, when the WT channel reaches maximal potentiation, the T352I mutant demonstrated no change in channel opening (Fig. $8 B, E$ ). Our single-channel analysis showed that the T352I mutation eliminates potentiation by ethanol without significantly altering basal function of the human BK channel.

\section{Discussion}

We screened C. elegans carrying missense mutations in the BK channel SLO-1 to identify conserved residues that are specifically required for intoxication but not for other BK channel-dependent behaviors. We identified one residue, T381, that when mutated to an isoleucine met these criteria and was conserved in the human BK channel as T352. Although we did not record from the worm SLO-1 channel, our subsequent analyses with in vivo and in vitro single-channel patch-clamp recordings of the human BK channel verified that the T352I mutation rendered the channel insensitive to activation by ethanol but otherwise largely preserved normal basal function. The conserved T352 residue identified in this study might be part of an ethanol-binding pocket, permit ethanol binding at another site, and/or occupy part of the channel that undergoes conformational changes during ethanol binding.

\section{The human BK channel can functionally replace the C. elegans BK channel}

The BK channel is highly conserved across species from invertebrates to humans, including the functional domains such as RCK1 and the $\mathrm{Ca}^{2+}$ bowl (Fodor and Aldrich, 2009). The worm and human $\mathrm{BK}$ channel both respond to $\mathrm{Ca}^{2+}$ and voltage depolarization, as well as the antagonists paxilline and iberiotoxin (Xia et al., 2002; Davies et al., 2003; Johnson et al., 2011). However, the conductance of the worm SLO-1 channel is vastly smaller (38 pS) than the conductance of the human BK channel (180-300 pS; Hille, 2001; Davies et al., 2003). This difference in conductance may explain why lower ethanol concentrations were able to produce intoxication in worms expressing the HSLO channel compared with the SLO-1 channel. Lower doses of ethanol may have been effective in producing a large potassium conductance from the human channel to suppress neuronal activity. Despite the large difference in conductance, the T381 residue appeared to be functionally equivalent to the human T352 residue since the mutation selectively abolished behavioral sensitivity to ethanol. In fact, this entire region is highly conserved-only two of the 20 closest residues to T381/352 are highly dissimilar between worms and humans. This region is also highly conserved in other species, including fly, cow, rat, and mouse. Because the mutant channel functioned normally in vitro and in vivo, we suspect that this residue represents a conserved site across species required for mediating intoxication that operates independent of the calcium and voltage activation.

\section{Behavioral genetic approach to identify critical residues for drugs}

Our "in vivo first" approach contrasts with conventional methodologies where an ion channel is first altered via site-directed mutagenesis at specific residues and studied with single-channel patch recordings in vitro in a heterologous system. A related conventional in vitro approach uses chimeras made of ethanol- 

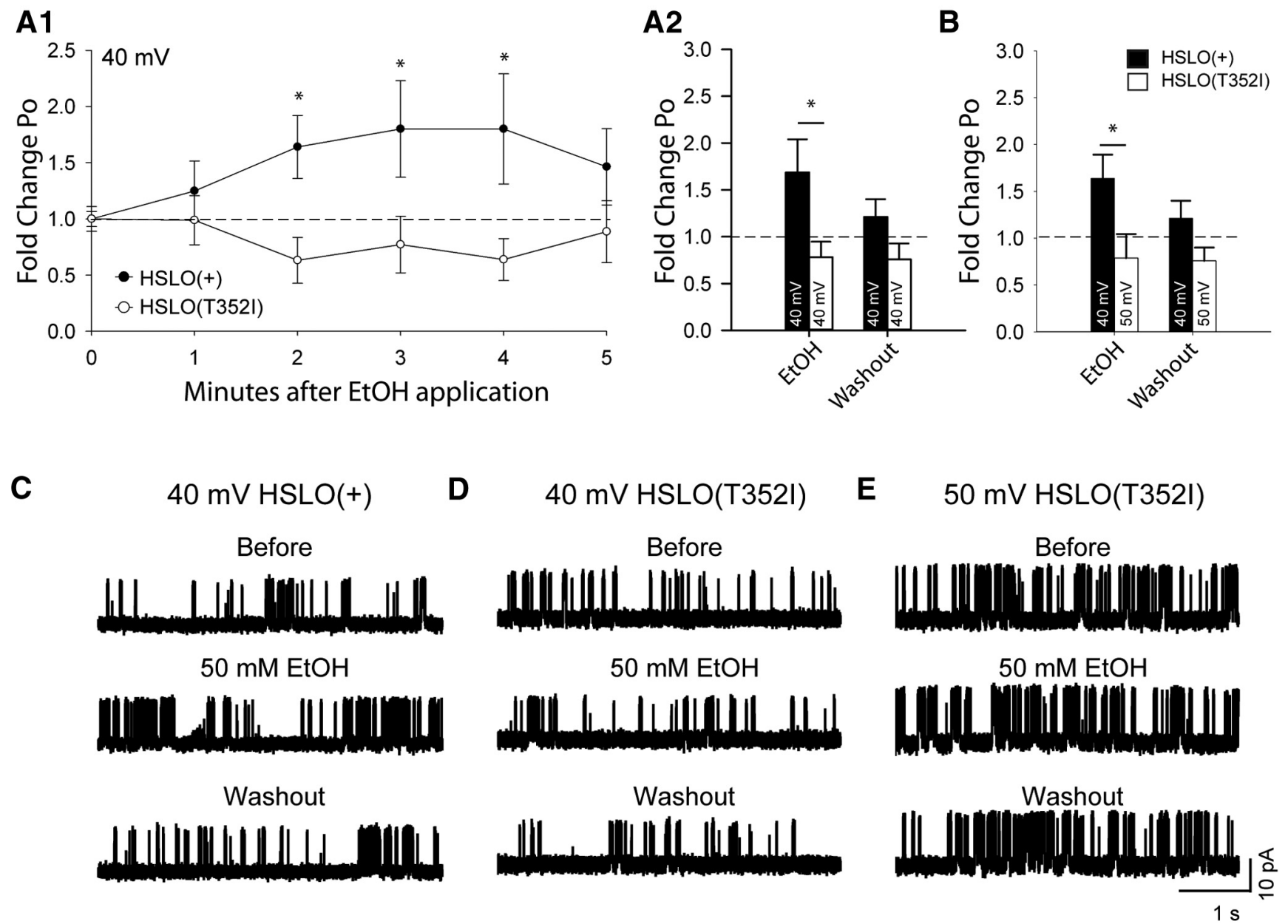

Figure 8. T352I mutant human BK channel is resistant to ethanol. Patches containing a single BK channel were tested for potentiation by ethanol in HEK cells. A1, Fold change in open probability $\left(P_{0}\right)$ during ethanol exposure. Baseline ( $4 \mathrm{~min}$ ) followed by EtOH application ( $5 \mathrm{~min}$ ), and washout (4 min). At $40 \mathrm{mV}$, ethanol application significantly potentiated WT compared withT352I mutant BK channels $(p<0.05)$. Post hoc analyses determined ethanol significantly potentiated WT compared with T352 mutant after $2 \min (p<0.05), 3 \min (p<0.05)$, and 4 min $(p<0.05)$ of ethanol application. A2, During the 5 min time course of ethanol application, the WT BK channel activity was significantly increased compared with the T352I mutant $(p<0.05)$. During washout, WT and mutant values for $P_{0}$ were indistinguishable $(p=0.23)$. $B$, WT BK channel held at $40 \mathrm{mV}$ was compared withT352I mutant at $50 \mathrm{mV}$ to control for subtle differences in basal opening $\left(40 \mathrm{mV} \mathrm{P}_{0}\right.$ WT $=$ 0.22 vs $50 \mathrm{mV} \mathrm{T352I}=0.26)$. WT BK channel showed increased $P_{0}$ after ethanol exposure $(2 \mathrm{~min} ; p<0.05)$, while T352I mutant did not. During washout, no significant difference was found between WT and mutant $(p=0.19)$. C, Representative WT BK channel currents at $40 \mathrm{mV}$ before, during $(2 \mathrm{~min})$, and after $50 \mathrm{~mm}$ ethanol, showing reversible increase in open probability. $\boldsymbol{D}$, Representative T352I BK channel currents under the same conditions in C show no potentiation by ethanol. E, Likewise, representative T352I BK channel currents held at $50 \mathrm{mV}$ show no potentiation. $(n=6$ recordings for each measurement in $A-E)$.

sensitive and -insensitive components of related ion channels (Mihic et al., 1997; Liu et al., 2003, 2013). While these conventional approaches are powerful and have proved successful, they cannot easily determine whether the mutations identified as important for ethanol effects in vitro are also relevant to ethanolmodulated behaviors in vivo. In addition, sometimes it is clear that the mutations identified from these in vitro approaches would be detrimental or fatal if the mutant channel replaced the wild-type in vivo. For instance, although single-residue mutations that render the glycine receptor S267 insensitive to ethanol have been known for over a decade, the knock-in replacement of the wild-type with the mutant channel resulted in post embryonic lethality shortly after birth. The abnormally low activity of the channel likely leads to fatal seizure activity (Findlay et al., 2005). These problems were finally overcome for the $\alpha 2 \mathrm{GABA}_{\mathrm{A}}$ receptor after a decade of searching for a distinct combination of S270H/L277A mutations that produce a viable mutant knock-in mouse with altered ethanol but not basal behaviors (Blednov et al., 2011; Harris et al., 2011). Thus, in vivo first ap- proaches may accelerate the discovery of ethanol-selective mutations for other targets of ethanol.

Additionally, because in vitro first conventional approaches generally postulate that positions showing divergence within an ion channel family contribute to differential drug sensitivities, conserved mechanisms important for drug action may be missed. Here we show that a relatively conservative substitution at T352 disrupts ethanol sensitivity. This residue is also conserved not just between different isoforms and across species, but also in other large conductance potassium channels like SLICK and SLACK that are not sensitive to ethanol (Lui et al., 2013). In a chimericbased in vitro approach, the T352 residue would not be targeted, and as a result never identified.

Liu et al. (2013) demonstrated the importance of the intracellular portion of the BK channel, and Liu et al. (2008) found that mutation of calcium-binding residues in the $\mathrm{Ca}^{2+}$ bowl and RCK1 domain abolished the ability of ethanol to activate the BK channel in vitro. However, mutations of the calcium-binding residues also dramatically alter calcium dependence and greatly re- 
duce voltage sensitivity (Schreiber and Salkoff, 1997; Xia et al., 2002). Such radical differences in function would be expected to produce changes in basal behaviors that would obscure any changes in ethanol-mediated behaviors. Our in vivo first approach overcomes these problems by screening a simple genetic model for missense mutations that abolish ethanol-dependent behaviors while leaving ethanol-independent behaviors intact. We identify a residue important for ethanol sensitivity earlier in the signal transduction pathway-before interaction with channel-gating mechanisms. Evidence for maintenance of basal function in worms was substantiated by in vivo rescue of ethanolindependent behaviors that are known to depend on BK channel function such as neck posture, egg laying, and aldicarb paralysis. Future studies will investigate whether the T381I mutation abolishes ethanol sensitivity at the single-channel level in SLO-1 like it does for HSLO. In principle, this approach could be applied to search for additional residues in the BK channel important for the actions of ethanol, or residues in other proteins involved in the actions of ethanol or other drugs. Importantly, this approach may be especially useful for drug targets that cannot be assessed easily at the molecular level.

\section{Implications for the role of BK channels in alcohol abuse behaviors}

It is remarkable that mutation of a single residue could have such a dramatic specific effect on ethanol modulation while minimally affecting basal BK channel function. Mutation of individual residues is also critical for ethanol-sensitive ligand-gated ion channels, highlighting the specificity of ethanol action on protein targets and eluding to binding sites for ethanol on channel proteins (Howard et al., 2014).

Identification of the T352I mutation elucidates a molecular basis of ethanol-dependent modulation of the BK channel. The T352 residue is positioned in the conserved RCK1 domain, which is thought to be critical for activation by intracellular calcium (Xia et al., 2002). This residue is not predicted to be a phosphorylation site (Blom et al., 1999; Huang et al., 2005; Dinkel et al., 2014). The T352I mutation results in a larger amino acid at position 352 and changes the residue from polar to nonpolar. Future studies will need to explore how alternative mutations at and near T352 influence ethanol responses of single channels. Such analyses might reveal whether this location provides a specific binding site for ethanol and/or represents a portion of the channel that undergoes conformational change in the presence of ethanol.

The BK channel has been implicated in behavioral responses to alcohol such as tolerance and consumption in mutant mice lacking BK channel auxiliary subunits (Martin et al., 2008; Kreifeldt et al., 2013). However, the basal behavioral impairments of the BK channel knock-out mouse have made it difficult thus far to probe the role of the channel itself. These results suggest that knocking in the T352I mutation in rodent models may alter ethanol-dependent behaviors without causing gross behavioral impairments, which would allow us to further advance our understanding of the role of the BK channel in alcohol-mediated behaviors.

\section{References}

Alaimo JT, Davis SJ, Song SS, Burnette CR, Grotewiel M, Shelton KL, PierceShimomura JT, Davies AG, Bettinger JC (2012) Ethanol metabolism and osmolarity modify behavioral responses to ethanol in C. elegans. Alcohol Clin Exp Res 36:1840-1850. CrossRef Medline

Blednov YA, Borghese CM, McCracken ML, Benavidez JM, Geil CR, Osterndorff-Kahanek E, Werner DF, Iyer S, Swihart A, Harrison NL,
Homanics GE, Harris RA (2011) Loss of ethanol conditioned taste aversion and motor stimulation in knockin mice with ethanol-insensitive $\alpha 2$-containing GABA(A) receptors. J Pharmacol Exp Ther 336:145-154. Medline

Blom N, Gammeltoft S, Brunak S (1999) Sequence and structure-based prediction of eukaryotic protein phosphorylation sites. J Mol Biol 294:13511362. CrossRef Medline

Brenner S (1974) The genetics of Caenorhabditis elegans. Genetics 77:71-94. Medline

Brodie MS, Scholz A, Weiger TM, Dopico AM (2007) Ethanol interactions with calcium-dependent potassium channels. Alcohol Clin Exp Res 31: 1625-1632. CrossRef Medline

Chase DL, Pepper JS, Koelle MR (2004) Mechanism of extrasynaptic dopamine signaling in Caenorhabditis elegans. Nat Neurosci 7:1096-1103. CrossRef Medline

Chen B, Liu P, Zhan H, Wang ZW (2011) Dystrobrevin controls neurotransmitter release and muscle $\mathrm{Ca}(2+)$ transients by localizing $\mathrm{BK}$ channels in Caenorhabditis elegans. J Neurosci 31:17338-17347. CrossRef Medline

Chu B, Treistman SN (1997) Modulation of two cloned potassium channels by 1-alkanols demonstrates different cutoffs. Alcohol Clin Exp Res 21: 1103-1107. CrossRef Medline

Chu B, Dopico AM, Lemos JR, Treistman SN (1998) Ethanol potentiation of calcium-activated potassium channels reconstituted into planar lipid bilayers. Mol Pharmacol 54:397-406. Medline

Cowmeadow RB, Krishnan HR, Atkinson NS (2005) The slowpoke gene is necessary for rapid ethanol tolerance in Drosophila. Alcohol Clin Exp Res 29:1777-1786. CrossRef Medline

Cowmeadow RB, Krishnan HR, Ghezzi A, Al'Hasan YM, Wang YZ, Atkinson NS (2006) Ethanol tolerance caused by slowpoke induction in Drosophila. Alcohol Clin Exp Res 30:745-753. CrossRef Medline

Cui J, Yang H, Lee US (2009) Molecular mechanisms of BK channel activation. Cell Mol Life Sci 66:852-875. CrossRef Medline

Davies AG, Pierce-Shimomura JT, Kim H, VanHoven MK, Thiele TR, Bonci A, Bargmann CI, McIntire SL (2003) A central role of the BK potassium channel in behavioral responses to ethanol in C. elegans. Cell 115:655666. CrossRef Medline

Dinkel H, Van Roey K, Michael S, Davey NE, Weatheritt RJ, Born D, Speck T, Krüger D, Grebnev G, Kuban M, Strumillo M, Uyar B, Budd A, Altenberg B, Seiler M, Chemes LB, Glavina J, Sánchez IE, Diella F, Gibson TJ (2014) The eukaryotic linear motif resource ELM: 10 years and counting. Nucleic Acids Res 42:D259-D266. CrossRef Medline

Dopico AM (2003) Ethanol sensitivity of $\mathrm{BK}(\mathrm{Ca})$ channels from arterial smooth muscle does not require the presence of the beta 1-subunit. Am J Physiol Cell Physiol 284:C1468-C1480. CrossRef Medline

Dopico AM, Anantharam V, Treistman SN (1998) Ethanol increases the activity of $\mathrm{Ca}(++)$-dependent $\mathrm{K}+(\mathrm{mslo})$ channels: functional interaction with cytosolic $\mathrm{Ca}++$. J Pharmacol Exp Ther 284:258-268. Medline

Dworetzky SI, Trojnacki JT, Gribkoff VK (1994) Cloning and expression of a human large-conductance calcium-activated potassium channel. Brian Res Mol Brain Res 27:189-193. CrossRef Medline

Findlay GS, Harris RA, Blednov YA (2005) Male transgenic glycine receptor alpha1 (S267Q) mutant mice display a hyperekplexia-like increase in acoustic startle responses. Pharmacol Biochem Behav 82:215-222. CrossRef Medline

Fodor AA, Aldrich RW (2009) Convergent evolution of alternative splices at domain boundaries of the BK channel. Annu Rev Physiol 71:19-36. CrossRef Medline

Golding NL, Jung HY, Mickus T, Spruston N (1999) Dendritic calcium spike initiation and repolarization are controlled by distinct potassium channel subtypes in CA1 pyramidal neurons. J Neurosci 19:8789-8798. Medline

Goodman MB, Hall DH, Avery L, Lockery SR (1998) Active currents regulate sensitivity and dynamic range in C. elegans neurons. Neuron 20:763772. CrossRef Medline

Hammarlund M, Jorgensen EM, Bastiani MJ (2007) Axons break in animals lacking beta-spectrin. J Cell Biol 176:269-275. CrossRef Medline

Harris RA, Osterndorff-Kahanek E, Ponomarev I, Homanics GE Blednov YA (2011) Testing the silence of mutations: transcriptomic and behavioral studies of GABA(A) receptor $\alpha 1$ and $\alpha 2$ subunit knock-in mice. Neurosci Lett 488:31-35. CrossRef Medline 
Hille B (2001) Ion channels of excitable membranes, Ed 3. Sunderland, MA: Sinauer.

Howard RJ, Trudell JR, Harris RA (2014) Seeking structural specificity: direct modulation of pentameric ligand-gated ion channels by alcohols and general anesthetics. Pharmacol Rev 66:396-412. CrossRef Medline

Huang HD, Lee TY, Tzeng SW, Horng JT (2005) KinasePhos: a web tool for identifying protein kinase-specific phosphorylation sites. Nucleic Acids Res 33:W226-W229. CrossRef Medline

Jakab M, Weiger TM, Hermann A (1997) Ethanol activates maxi Ca2+activated $\mathrm{K}+$ channels of clonal pituitary (GH3) cells. J Membr Biol 157:237-245. CrossRef Medline

Johnson BE, Glauser DA, Dan-Glauser ES, Halling DB, Aldrich RW, Goodman MB (2011) Alternatively spliced domains interact to regulate BK potassium channel gating. Proc Natl Acad Sci U S A 108:20784-20789. CrossRef Medline

Kapfhamer D, Bettinger JC, Davies AG, Eastman CL, Smail EA, Heberlein U, McIntire SL (2008) Loss of RAB-3/A in Caenorhabditis elegans and the mouse affects behavioral response to ethanol. Genes Brain Behav 7:669676. CrossRef Medline

Kim H, Pierce-Shimomura JT, Oh HJ, Johnson BE, Goodman MB, McIntire SL (2009) The dystrophin complex controls bk channel localization and muscle activity in Caenorhabditis elegans. PLoS Genet 5:e1000780. CrossRef Medline

Kreifeldt M, Le D, Treistman SN, Koob GF, Contet C (2013) BK channel $\beta 1$ and $\beta 4$ auxiliary subunits exert opposite influences on escalated ethanol drinking in dependent mice. Front Integr Neurosci 7:105. CrossRef Medline

Lancaster B, Nicoll RA (1987) Properties of two calcium- activated hyperpolarizations in rat hippocampal neurones. J Physiol 389:187-203. Medline

Liu J, Asuncion-Chin M, Liu P, Dopico AM (2006) CaM kinase II phosphorylation of slo Thr107 regulates activity and ethanol responses of BK channels. Nat Neurosci 9:41-49. CrossRef Medline

Liu J, Vaithianathan T, Manivannan K, Parrill A, Dopico AM (2008) Ethanol modulates BKCa channels by acting as an adjuvant of calcium. Mol Pharmacol 74:628-640. CrossRef Medline

Liu J, Bukiya AN, Kuntamallappanavar G, Singh AK, Dopico AM (2013) Distinct sensitivity of slo1 channel proteins to ethanol. Mol Pharmacol 83:235-244. CrossRef Medline

Liu P, Liu J, Huang W, Li MD, Dopico AM (2003) Distinct regions of the slo subunit determine differential BKCa channel responses to ethanol. Alcohol Clin Exp Res 27:1640-1644. CrossRef Medline

Mahoney TR, Luo S, Nonet ML (2006) Analysis of synaptic transmission in Caenorhabditis elegans using an aldicarb-sensitivity assay. Nat Protoc 1:1772-1777. CrossRef Medline
Martin GE, Hendrickson LM, Penta KL, Friesen RM, Pietrzykowski AZ, Tapper AR, Treistman SN (2008) Identification of a BK channel auxiliary protein controlling molecular and behavioral tolerance to alcohol. Proc Natl Acad Sci U S A 105:17543-17548. CrossRef Medline

Mihic SJ, Ye Q, Wick MJ, Koltchine VV, Krasowski MD, Finn SE, Mascia MP, Valenzuela CF, Hanson KK, Greenblatt EP, Harris RA, Harrison NL (1997) Sites of alcohol and volatile anaesthetic action on GABA(A) and glycine receptors. Nature 389:385-389. CrossRef Medline

Milescu LS, Nicolai C, Bannen J (2000) 2000-2013 QuB Software.

Pierce-Shimomura JT, Chen BL, Mun JJ, Ho R, Sarkis R, McIntire SL (2008) Genetic analysis of crawling and swimming locomotory patterns in $C$. elegans. Proc Natl Acad Sci U S A 105:20982-20987. CrossRef Medline

Robitaille R, Garcia ML, Kaczorowski GJ, Charlton MP (1993) Functional co-localization of calcium and calcium-gated potassium channels in control of transmitter release. Neuron 11:645-655. CrossRef Medline

Schreiber M, Salkoff L (1997) A novel calcium-sensing domain in the BK channel. Biophys J 73:1355-1363. CrossRef Medline

Shen KZ, Lagrutta A, Davies NW, Standen NB, Adelman JP, North RA (1994) Tetraethylammonium block of Slowpoke calcium-activated potassium channels expressed in Xenopus oocytes: evidence for tetrameric channel formation. Pflugers Arch 426:440-445. CrossRef Medline

Thompson O, Edgley M, Strasbourger P, Flibotte S, Ewing B, Adair R, Au V, Chaudhry I, Fernando L, Hutter H, Kieffer A, Lau J, Lee N, Miller A, Raymant G, Shen B, Shendure J, Taylor J, Turner EH, Hillier LW, et al. (2013) The million mutation project: a new approach to genetics in Caenorhabditis elegans. Genome Res 23:1749-1762. CrossRef Medline

Waggoner LE, Zhou GT, Schafer RW, Schafer WR (1998) Control of alternative behavioral states by serotonin in Caenorhabditis elegans. Neuron 21:203-214. CrossRef Medline

Walters FS, Covarrubias M, Ellingson JS (2000) Potent inhibition of the aortic smooth muscle maxi-K channel by clinical doses of ethanol. Am J Physiol Cell Physiol 279:C1107-C1115. Medline

Wang ZW, Saifee O, Nonet ML, Salkoff L (2001) SLO-1 potassium channels control quantal content of neurotransmitter release at the C. elegans neuromuscular junction. Neuron 32:867-881. CrossRef Medline

Xia XM, Zeng X, Lingle CJ (2002) Multiple regulatory sites in largeconductance calcium-activated potassium channels. Nature 418:880884. CrossRef Medline

Yuan C, O'Connell RJ, Wilson A, Pietrzykowski AZ, Treistman SN (2008) Acute alcohol tolerance is intrinsic to the BKCa protein, but is modulated by the lipid environment. J Biol Chem 283:5090-5098. Medline

Zar JH (1999) Biostatistical analysis, Ed 4. Upper Saddle River, NJ: Prentice Hall. 